\title{
ENTREVISTA CON ERNESTO GARZÓN VALDÉS
}

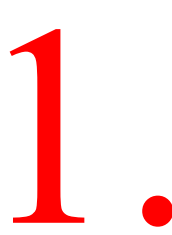

- La filosofía del Derecho argentina de las tres o cuatro últimas décadas (desde la época de Cossio) es un fenómeno que a muchos les resulta sorprendente. En un medio que, en muchos aspectos, parece sumamente adverso, se ha desarrollado un movimiento de filosofia del Derecho que hoy goza de un reconocimiento internacional. ¿Cuáles consideras que son las claves de este «éxito» cultural? ¿Cómo ves la situación actual y las perspectivas de futuro? ¿Cuál consideras que ha sido tu papel en este movimiento? ¿Qué temas se cultivan hoy preferentemente y cuáles son las tendencias iusfilosóficas predominantes? ¿Cuáles son tus relaciones con la cultura de tu país -en particular con la cultura filosófico-jurídicadespués de tantos años de estancia en Alemania?

La Argentina, sobre todo Buenos Aires, no obstante estar situada geográficamente en la periferia del mundo cultural al que pertenece ha tenido siempre una fuerte tendencia a superar todo provincianismo y a mantener una gran apertura a todas las corrientes del pensamiento europeo. Ya en época de la colonia, el hecho de que el Virreinato del Río de la Plata no tuviera mayor interés económico para la Corona española contribuyó a que Buenos Aires buscara un mayor contacto, también intelectual, con otros países europeos, principalmente Inglaterra. Esta tradición fue continuada después de la independencia durante todo el siglo XIX (basta leer la obra de Esteban Echeverría o de Domingo F. Sarmiento para comprobarlo). En el siglo XX, abiertas ya las puertas del país a la inmigración, se acentuó aún más esta actitud. Sería desde luego aventurado afirmar categóricamente que esta versión hacia el exterior ha sido en todos los casos beneficiosa y que ella no ha afectado negativamente aspectos tan fundamentales como puede ser la propia identidad del argentino. Pero lo que sí parece indiscutible es que esta tendencia universalista ha favorecido la actividad científica en general y, en nuestro caso, la reflexión iusfilosófica.

Con respecto a la filosofía del derecho, creo que hay que mencionar. además, los siguientes aspectos:

a) Los magisterios de Carlos Cossio y, sobre todo, de Ambrosio Gioja. En mis ya largas y variadas experiencias universitarias en el exterior, no he conocido a nadie que como Gioja estuviera tan francamente abierto al diálogo, tan dispuesto a someter a crítica las propias posiciones y con una sensibilidad tan afinada para percibir cuáles eran las corrientes innovadoras del pensamiento jurídico que no podían ser ignoradas, cualquiera que fuera su procedencia. 
b) Una activa política de traducciones de obras jurídicas fundamentales: Ya en 1962, Genaro R. Carrió tradujo Sobre el derecho y la justicia, de Alf Ross y en 1963, es decir, dos años después de su publicación en Oxford, El concepto de derecho, de H. L. A. Hart. Ambas obras fueron objeto no sólo de seminarios para docentes sino también textos obligatorios en los cursos de filosofía del derecho.

c) Las frecuentes visitas de juristas y filósofos extranjeros: A. Aarnio, H. Albert, K. O. Apel, M. Atienza, N. Bobbio, J. Bochenski, D. Davidson, R. Dworkin, E. Díaz, R. Hilpinen, U. Klug, F. Laporta, F. Miró Quesada, T. Nagel, A. Peczenik, J. Raz, A. Ross, A. Rossi, E. Sosa, P. Strawson, L. Villoro, O. Weinberger, B. Williams, G. H. von Wright, J. Wroblewski y muchos otros. Dadas las distancias (una ventaja más de la excentricidad geográfica argentina), estas visitas no se limitaban a la simple conferencia aislada y más o menos brillante, sino que, por lo general consistían en cursillos que a su vez habían sido preparados a través de la lectura de las obras del respectivo visitante e iban acompañados de intensas discusiones. Teniendo en cuenta estas circunstancias, no resulta exagerada la afirmación de Alf Ross cuando en el prefacio a la edición castellana de Sobre el derecho y la justicia, dice: "Cuando hace un par de años tuve el honor de ser invitado a dar conferencias en la Facultad de Derecho de la Universidad Nacional de Buenos Aires, me impresionó mucho el papel que allí desempeña la filosofía en la enseñanza del derecho. Hallé entre mis colegas en ese campo un conocimiento, un interés y una comprensión mucho mayores que la que es común encontrar en mi país». En algunos casos, este diálogo influía también en el pensamiento del visitante. Con su ejemplar honestidad intelectual, G. H. von Wright se ha referido en este sentido a su primera visita a la Argentina: «... fui invitado a dar conferencias... en la Universidad Nacional de La Plata, Argentina. Mantuve también fecundas discusiones con varios miembros del Instituto de Filosofía del Derecho de la Universidad de Buenos Aires. Debo al profesor Carlos Alchourrón una importante corrección en mi tratamiento anterior del cálculo deóntico diádico» (en el prólogo a su $A n$ Essay in Deontic Logic and the General Theory of Action, pág. 5, Amsterdam 1968).

d) La creación de un foro de diálogo e investigación que no estuviera sometido a los vaivenes de una política, por lo general dictatorial, que no se detenía ante las puertas de la universidad: SADAF (Sociedad Argentina de Análisis filosófico).

e) Los viajes de estudios de filósofos del Derecho argentinos, principalmente a Oxford y a la República Federal de Alemania, durante los años 60 y 70, a la vez que el establecimiento de un contacto regular y casi institucionalizado con colegas latinoamericanos dedicados a temas de filosofía analítica y lógica, como Alejandro Rossi, Fernando Salmerón y Luis Villoro en México y Francisco Miró Quesada en el Perú.

f) La disposición a la polémica y la crítica de un grupo cuyos miembros, de las más diversas edades y posiciones universitarias, sólo respetaban los principios de la tolerancia y la racionalidad. Recuerdo una noche, a mediados de los 60, haber recorrido medio Buenos Aires discutiendo 
acaloradamente con Carlos S. Nino acerca de la teoría finalista de la acción en Hans Welzel. Durante casi cuatro años, con Nino, María Eugenia Urquijo y Norberto Spolansky nos reunimos todas las semanas a discutir sobre temas de teoría de la acción, con miras a publicar un libro que nunca vio la luz y que muchos años después sirviera de remoto impulso a la Introducción a la filosofía de la acción humana (Buenos Aires, 1987) de Carlos S. Nino.

Creo que estas circunstancias y talantes nos permitieron sobrevivir intelectualmente en un ambiente convulsionado por reiterados golpes militares que interrumpían los breves intentos de democracia civil. Este microclima que nos habíamos creado hizo posible que Genaro R. Carrió publicara en 1964 sus Notas sobre derecho y lenguaje y Carlos Alchourrón y Eugenio Bulygin la Introducción a la metodología de las ciencias jurídicas y sociales (1971).

Por lo que a mí respecta, pienso que mi vinculación con la Universidad Nacional de Córdoba me permitió llevar al interior del país muchas de las preocupaciones del grupo de Buenos Aires y formar así a jóvenes que, después de la dura pausa impuesta por la dictadura militar de 1976-1983, han asumido cargos de docencia e investigación y practican las mismas reglas del trabajo intelectual a las que me he referido. También desde Córdoba, con la Biblioteca de Filosofía del Derecho y Sociología, procuré facilitar el conocimiento de filósofos del Derecho alemanes como H. Kelsen, G. Radbruch o H. Welzel. Tal vez mi libro sobre Derecho y «naturaleza de las cosas» sirvió en alguna medida para estimular el rechazo de concepciones iusfilosóficas basadas en principios de dudosa racionalidad y en este sentido fue un aporte a una limpieza intelectual, practicada en la década de los 60 desde la perspectiva de la filosofía analítica.

Tres son posiblemente los temas que más interesan en la actualidad a los filósofos argentinos del derecho: a) Cuestiones de lógica deóntica. Ello no es sorprendente dada la presencia en Buenos Aires de Carlos Alchourrón y Eugenio Bulygin. b) Aspectos de la teoría del derecho vinculados principalmente con la estructura del sistema normativo y con problemas de la sistematización de la dogmática jurídica. Nombres como los de Ricardo Caracciolo, Ricardo Guibourg o Roberto Vernengo, ilustran esta corriente. c) Cuestiones de ética jurídico-política. Martín Diego Farrell y Carlos S. Nino son en mi opinión los más distinguidos representantes de esta línea de investigación que ha adquirido creciente importancia y en cuya discusión intervienen también iusfilósofos de las otras dos corrientes.

No obstante mi obligada ausencia del país durante casi una década, mantuve permanente contacto con la filosofía jurídica argentina de orientación analítica. La mayoría de mis amigos de Buenos Aires viajaron en esos años con frecuencia a Europa recurriendo al más variado repertorio de recursos: becas, invitaciones a congresos y generosas financiaciones en las que ha jugado un papel significativo la España democrática. Tal vez la más clara expresión de mi contacto con la filosofía del Derecho argentina sea el libro Argentinische Rechtstheorie und Rechisphilosophie 
heute, que editara recientemente en Berlín (Oeste) con Eugenio Bulygin.

2. -En el número 1 de DOXA, en tu contestación a la encuesta planteada allí, y a propósito de tu trayectoria como filósofo del Derecho, expones cuáles son los temas abordados y los resultados alcanzados, pero omites cualquier referencia de tipo biográfico, como por ejemplo, tus relaciones con los dos grandes «maestros» de la filosofía del Derecho argentina del siglo XX (Cossio y Gioja), etc. ¿Podrías completar ahora estos datos de tu «ficha personal» como iusfilósofo?

No es fácil precisar las motivaciones que le impulsan a uno a trabajar en un campo determinado del conocimiento. Cuando se mira hacia atrás, se tiene la sensación de que uno podría haber hecho las cosas mucho mejor pero no que hubiera hecho otras muy diferentes. Nunca dudé que quería estudiar Derecho y que lo que más me interesaba era el aspecto teórico de esta disciplina. La profesión de abogado me atraía poco o nada; sólo la ejercí durante un año con un desastroso resultado económico. En España, a comienzos de los 50, la influencia sobre todo de Xavier Zubiri y de Enrique Gómez Arboleya, reforzaron mi vocación por la filosofía y las ciencias sociales. Los años de Madrid (1951-1953) fueron para mí decisivos. Había salido de Córdoba al día siguiente de recibirme de abogado, en diciembre de 1950, asfixiado por el clima de una universidad en la que imperaban lemas tales como «Alpargatas sí, libros no» o «Haga patria, mate un estudiante». Mario Bunge ha descrito cabalmente el ambiente académico de aquella época: «Un amasijo de mentiras, trivialidades, cursilerías, rosismo y catolicismo...».

No obstante las limitaciones del régimen franquista, el ambiente intelectual del Madrid que yo viví era incomparablemente más abierto y estimulante que el que había vivido en Córdoba bajo el segundo gobierno de Perón: en 1951 fue designado ministro de Educación Nacional Joaquín Ruiz Giménez, con lo que se inició un período de liberalización universitaria. Rector de la Universidad de Madrid era Pedro Laín Entralgo y de la de Salamanca, Antonio Tovar. Xubiri dictaba cursos privados en cuya organización se turnaban Laín y Gómez Arboleya. Al referirse a esos años, Elías Díaz ha señalado con razón: «Era indudable que, a pesar de las muy desfavorables circunstancias del país... se había comenzado a producir una vida intelectual de considerable importancia y de un digno nivel científico en la España de esos años». (Pensamiento español 1939-1975, Madrid 1978, 100 S.).

Luego vinieron los seminarios de Karl Engisch en Munich (1954-1956) y así, poco a poco, me vi transitando una vía que me parecía tan natural que creo no podría haber elegido otra.

Justamente por haber salido de la Argentina apenas recibido, a Carlos Cossio lo conocí mucho después de haberlo leído: a mediados de los 
sesenta. Mis contactos personales con él fueron cordiales pero esporádicos. Con Gioja, en cambio, mantuve desde mi regreso a la Argentina en 1964 hasta su muerte en 1971, una fecunda relación intelectual y humana. Su liberalidad, su disposición a aprender también de sus discípulos, a corregir los propios errores, creo que influyeron decididamente en mi actitud como profesor universitario.

3. -En tu reciente trabajo sobre El concepto de estabilidad de los sistemas políticos utilizas el concepto hartiano de regla de reconocimiento como «criterio supremo de la identidad del sistema» politico y hablas de «cambio de la regla de reconocimiento» para referirte a aquellos hechos a los que, en la terminología política corriente, se suele aludir como «cambio de régimen político». Es de suponer que lo haces así no sólo porque, como dices en tu trabajo, cuando "hablamos de sistemas politicos necesariamente tenemos que referirnos a enunciados que describen reglas y formas de comportamiento que están vinculadas entre sí por criterios de indole normativa», sino también porque el concepto de «regla de reconocimiento» tiene, pese a su complejidad, un grado de precisión mayor que el concepto de "régimen». Concordamos, desde luego, contigo en que la regla de reconocimiento "en ningún caso se agota en las disposiciones de una norma constitucional, sino que incluye también principios, máximas, criterios para la aplicación de las reglas del sistema». Pero, aun así, parece que has ampliado el contenido de la regla de reconocimiento para abarcar elementos que, al menos en el contexto de uso originario de esta expresión, el de la teoría del Derecho, no son tomados en consideración. Por ejemplo, refiriéndote a la regla de reconocimiento correspondiente al sistema político costarricense incluyes en el contenido de la misma «un modelo de desarrollo que responde al esquema de un capitalismo de Estado-benefactor» y, respecto al sistema político venezolano, incluyes en un listado de los «elementos esenciales» de su regla de reconocimiento «la aceptación de la necesidad de diversificar las exportaciones y de una industrialización que permita sustituir las importaciones y reducirla dependencia del petróleo». Quizá podría objetarse que tu intento de hacer operativo el concepto de regla de reconocimiento en un contexto de problemas distinto de aquél para el que fue pensado ha tenido como precio la desnaturalización del propio concepto, con lo que la ventaja de su mayor precisión respecto al de «régimen político», u otros análogos, se habría perdido. ¿Estarías de acuerdo con ello? ¿Hasta dónde, y bajo qué condiciones, son en tu opinión utilizables en el campo de la teoría política conceptos típicos de la teoría del Derecho? Y, más en general, ¿cómo ves la relación entre estas dos disciplinas?

En mi trabajo sobre el concepto de estabilidad de los sistemas políticos, lo que me interesaba era encontrar un criterio que me permitiera identificar el sistema del que había que predicar su estabilidad o inestabilidad. 
Cuando uno analiza la literatura sobre este tema, no puede menos que quedar sorprendido ante la falta casi absoluta de criterios de identificación. En el mejor de los casos, suele recurrirse a criterios puramente formales como la Constitución del país en cuestión o más o menos vagos, como la ideología dominante. En ambos casos resulta difícil establecer una distinción clara entre los conceptos de estabilidad, legitimación y legitimidad, que en mi trabajo juega un papel fundamental.

La concepción hartiana del «punto de vista interno» (estrechamente vinculada con la de «regla de reconocimiento») me pareció sumamente útil para explicar lo que entiendo por «legitimación». Es verdad, como también lo he señalado, que este «punto de vista interno» no es muy diferente de lo que Max Weber llamaba «creencia en la legitimidad»; me pareció, sin embargo, que la expresión hartiana tenía la ventaja de una menor carga emotiva, y que ello permitía evitar más fácilmente la confusión entre «legitimación» y «legitimidad».

Tenéis desde luego razón cuando afirmáis que quizás he extendido el campo de denotación de la «regla de reconocimiento». Pienso que esto era inevitable si se quería hablar de sistemas políticos y no estrictamente jurídicos. Pero creo que el sentido sigue siendo el mismo. Por ejemplo, cuando en el caso venezolano digo que su «regla de reconocimiento» incluye «la aceptación de la necesidad de diversificar las exportaciones», esto podría reformularse en un lenguaje más estrictamente hartiano diciendo que entre los principios o máximas de la «regla de reconocimiento» figura el rechazo de aquellas normas que tiendan a establecer una relación de dependencia total con respecto a ciertos mercados. Quienes desearan imponer tales normas entrarían en contradicción con la «regla de reconocimiento» del sistema. Creo que estaríais dispuestos a aceptar que a la «regla de reconocimiento» del sistema español, por ejemplo, pertenece, como enfáticamente lo ha señalado Gregorio Peces Barba en sus publicaciones sobre el tema, el principio del Estado social de derecho, de acuerdo con el artículo 1,1 de la Constitución de 1978. Pero la fórmula «Estado social», implica, desde luego, la aceptación de un sistema de seguridad social, de la vigencia de deberes positivos de asistencia, que responden también a una concepción de las estructuras económicas del país. Que se trate de un modelo de «capitalismo de Estado-benefactor» (como en el caso de Costa Rica) o no, es algo que me parece irrelevante para la cuestión que aquí nos ocupa. Y si queréis otro ejemplo de disposiciones constitucionales que describen con lujo de detalles un determinado modelo de desarrollo podéis tomar el artículo 27 de la Constitución mexicana de 1917 referido a los derechos de propiedad de las tierras y aguas. Dicho con otras palabras: si se está dispuesto a aceptar que las disposiciones constitucionales tienen alguna relevancia para la formulación de la «regla de reconocimiento», no veo por qué han de resultar tan extrañas precisiones como las que formulara con respecto a los sistemas costarricence o venezolano que, en verdad, sólo glosan artículos de las respectivas Constituciones.

Concedo, sin embargo, que a un jurista, la expresión «regla de reconocimiento», utilizada en el contexto de la politología, puede provocarle ciertas dudas. Este suele ser el inconveniente del traspaso de expresiones 
acuñadas en una determinada disciplina al campo de otros campos del conocimiento, por más afines que estos puedan ser.

La obra de Max Weber y, si se quiere recurrir a ejemplos actuales, el libro de Norman P. Barry An Introduction to Modern Political Theory (Hong Kong, 1981) demuestran la posibilidad de utilizar con éxito conceptos jurídicos para explicar fenómenos políticos e ilustran la fecundidad de un trabajo interdisciplinario entre la teoría del Derecho y la de la política.

4. -Recientemente has escrito diversos trabajos adscribibles al campo de la filosofía política y en los que abordas problemas vinculados con la realidad política latinoamericana. Uno de ellos, La democracia argentina actual: Problemas ético-políticos de la transición, puede entenderse que constituye -aunque en él están presentes los instrumentos conceptuales y la destreza argumentativa del filósofo- una mera intervención qua ciudadano en el problema capital del debate político de tu país. Pero otros -el referente al concepto de estabilidad de los sistemas políticos, del que hablábamos antes, o el dedicado al paternalismo en las relaciones internacionales- parecen obedecer a motivaciones menos circunstanciales. ¿Podría interpretarse esto como un propósito deliberado de cultivar la filosofía política, después de haber hecho lo propio con la filosofia del Derecho y con la filosofía moral? ¿Qué papel ocupa en tu obra la reflexión sobre Latinoamérica? Dejando por un momento al lado la teoría, ¿cómo te definirías desde el punto de vista ideológico-político? ¿Cuál es tu actitud, en cuanto ciudadano, respecto a los problemas políticos básicos?

En 1975, poco antes de ser designado profesor en el Instituto de Politología de Maguncia, conversando con Joseph Raz en Oxford, le expresé mis dudas acerca de la conveniencia de dedicarme a la filosofía política pues pensaba que ello me alejaría fatalmente de los temas que hasta entonces había cultivado. Raz se limitó a preguntarme: ¿crees que los temas son realmente tan distintos? Y la verdad es que cuando uno analiza las cosas más de cerca no es difícil comprobar que se trata de una problemática muy afín en la que los conocimientos del jurista pueden ser útiles para evitar que la politología se transforme en una especie de periodismo con notas al pie de página, que tan sólo se limita a combinar alguna descripción de la realidad con una buena dosis de ideología casi siempre cargada de emociones circunstanciales. En mi trabajo sobre lo que llamara la «paradoja de Johnson» intenté ilustrar la insuficiencia de aquellos análisis politológicos que pretenden formular predicciones de comportamientos políticos con total prescindencia de aquella precisión conceptual a la que solemos estar acostumbrados los juristas.

La actitud de distanciamiento analítico no significaba desde luego que uno pueda escapar al contexto vital que le ha tocado en suerte. No conozco filósofo del derecho que, por más objetivo que pretenda ser, no deje entrever su posición política básica. Basta pensar en nombres 
como Kelsen, Ross, Bobbio o Hart. Por lo que a mí respecta, me definiría como socialdemócrata que acepta los principios del liberalismo político pero no su versión económica. La expresión «liberalismo» puede inducir a error, sobre todo en los países hispánicos. Por ello una breve precisión: tal como he procurado demostrarlo en mi artículo sobre la fundamentación de los deberes positivos generales, pienso que quien está dispuesto a aceptar la vigencia de deberes negativos como condición necesaria para la convivencia de seres racionales y autónomos, no puede quedarse a medio camino y negar la obligatoriedad ética de los deberes positivos. En este sentido, justificar el Estado de derecho significa también justificar el Estado social de derecho. Si se acepta que tal es el caso, el reconocimiento de estos valores éticos no puede limitarse a una reflexión teórica sino que debe expresarse en la vida cotidiana como ciudadano. La experiencia del exilio me ha enseñado que adoptar actitudes de una cierta coherencia entre lo que uno piensa y la forma como uno actúa es mucho más fácil que lo que suele creerse. Salvo casos extremos, ello no requiere esfuerzos heroicos sino un mínimo de evaluación de lo que está en juego.

Suele decirse en la Argentina que en Córdoba comienza América Latina. Tal vez haya algo de cierto en esta afirmación. En todo caso, siempre me he sentido profundamente latinoamericano. La convivencia con latinoamericanos en Madrid posiblemente reforzó en mí esta actitud. En los últimos años, también por razones universitarias, he tenido que dedicarme a temas latinoamericanos. Y debo admitir que el estudio de la historia y la realidad de América Latina no suele contribuir a estimular mi optimismo. La esperanza de mejoras substanciales creo que es menor a fines del siglo XX que a su comienzo. La esperanza no es ahora fácil, como diría Borges. Descripciones de la sociedad latinoamericana escritas en el siglo XVI, como las crónicas del Inca Garcilaso, o en el XIX como las de Flora Tristán, no se diferencian mucho de las más recientes de Carlos Fuentes o de Juan Uslar Pietri. Esta persistente actualidad de los rasgos distintivos de una sociedad no deja de ser desalentadora y a quienes nos dedicamos a temas de filosofía política y jurídica nos impone el deber de asumir los problemas con la mayor objetividad posible pero también con una buena dosis de compromiso político-social. Algo de esto he procurado expresar en mis trabajos sobre las clases medias en América Latina, sobre la función del derecho en ese continente y sobre el fenómeno de la emigración argentina a partir de la década de los cincuenta. Se trata, pienso, de una tarea que consiste en ir eliminando los velos con que solemos encubrir nuestra precaria situación y en asumir la cuota de responsabilidad que a cada uno le incumbe. Ello por cierto no es fácil dadas las condiciones objetivas de dependencia externa que padece América Latina. Pero hay un campo de actitudes subjetivas en el que sí es posible introducir cambios relevantes. Se trata aquí de intentar superar las inconsecuencias causales que están presentes en casi todos los modelos de desarrollo político-social que se han formulado en el subcontinente. Los ejemplos que expongo en mi libro sobre el concepto de estabilidad ilustran esta desarmonía básica entre lo que queremos ser y los medios que utilizamos para obtener nuestros fines. Vistas así 
las cosas, el subdesarrollo de América Latina no es sorprendente sino más bien la consecuencia inevitable de una relación de dependencia a la que se suma la pretensión de querer fines sin estar dispuesto a cumplir con las condiciones necesarias para alcanzarlos. Y querer algo sin querer al mismo tiempo aquello que es condición necesaria para obtener lo querido puede ser en muchos casos una prueba clara de irracionalidad.

5. -Probablemente no haya ningún otro intelectual que conozca tan bien como tú la vida cultural -en particular en el sector de las ciencias sociales-alemana, española y argentina. ¿Podrías trazarnos un cuadro comparativo entre estos tres países desde el punto de vista de las instituciones universitarias? ¿Cómo valoras en particular la situación actual de la filosofía jurídica y social?

Una respuesta más o menos precisa a esta pregunta implicaría superar ampliamente el marco de esta entrevista. Me limitaré pues a algunas consideraciones puntuales.

Con respecto al caso alemán, pienso que desde hace algunas décadas, una gran parte de la intelectualidad alemana, a veces a través del rodeo anglosajón, ha vuelto a recuperar lo mejor de una tradición interrumpida por la barbarie nazi. Que esta recuperación no es total lo demuestra la llamada «polémica de los historiadores» motivada por un intento de trivializar o relativizar los crímenes del nacional socialismo a través de la comparación con otros regímenes como el impuesto por Stalin en la Unión Soviética. Pero también la reacción ante esta empresa por parte de filósofos como J. Habermas o E. Tugendhat, pone de manifiesto que hay una corriente de pensamiento -por lo demás la más significativa de la Alemania Federal- que toma muy en serio la responsabilidad del intelectual ante los problemas de su sociedad. En el caso concreto de la filosofía del Derecho, esta disciplina se ha beneficiado enormemente del trabajo de filósofos no especializados en temas jurídicos pero que en creciente medida se ocupan de problemas de filosofía práctica y por ello también de cuestiones vinculadas con la justificación de los sistemas normativos. Basta recordar los nombres de Günther Patzig, Eike von Savigny, Karl O. Appel, Jürgen Habermas, Hans Lenk, Hermann Lübbe, Ernst Tugendhat, Hans Albert o Hartmut Kliemt. Al hablar de la filosofía del derecho alemana, no puedo dejar de señalar el interés de muchos de sus representantes por la filosofía del derecho de habla hispana. Werner Krawietz, desde Rechtstheorie, promueve constantemente la publicación de autores del mundo hispánico: en los últimos años han aparecido en esta prestigiosa revista artículos, por ejemplo, de Elías Díaz, León Olivé, Antonio Enrique Pérez Luño, Carlos S. Nino, Albert Calsamiglia y muchos otros.

Cuando se habla de la filosofía jurídica española actual no es posible dejar de mencionar la labor de docencia e investigación de por lo menos tres profesores: Elías Díaz, Juan Ramón Capella y Gregorio Peces 
Barba, ni tampoco olvidar la obra de orientación científica de Felipe González Vicén. La recuperación de la tradición liberal y socialista española, impulsada sobre todo por Elías Díaz, Francisco Laporta, Virgilio Zapatero y Eusebio Fernández, así como la recepción de autores fundamentales como Alf Ross (Liborio Hierro), Norberto Bobbio (Alfonso Ruiz Miguel) y H. L. A. Hart (Juan Ramón de Páramo) han contribuido a ampliar los horizontes de la discusión iusfilosófica, que también ha ido acompañada de estudios sobre los problemas jurídico-políticos de la transición, como los de Luis García San Miguel.

Superadas las limitaciones del régimen franquista, es innegable la presencia en España de todo un grupo de jóvenes jusfilósofos que han asumido con rigor científico el tratamiento de los problemas de la teoría y la filosofía del Derecho a la vez que mantienen una actitud de franco rechazo de todo provincianismo intelectual. También en muchos casos la provincia española ha dejado de ser provinciana: el hecho de que en Alicante se edite «Doxa», desde Zaragoza Juan José Gil Cremades dirija el «Anuario de Filosofía del Derecho» o en la Universidad del País Vasco, por iniciativa de Miguel Sánchez Mazas, se celebren periódicos coloquios sobre teoría de la ciencia en el que participan figuras de relieve internacional son sólo dos ejemplos de esta superación de falsos centralismos. La filosofía del Derecho -no sólo la española- resulta también beneficiada por la presencia de iusfilósofos en instituciones claves; no es difícil percibir la fecunda labor de promoción científica que realiza Francisco Laporta desde el Centro de Estudios Constitucionales. Los contactos con América Latina se manifiestan en un permanente diálogo que incluye valiosas investigaciones monográficas, como en el caso del libro de Manuel Atienza La Filosofía del Derecho argentina actual, o en la publicación de autores latinoamericanos propiciada por Albert Calsamiglia en Barcelona, por Elías Díaz en Madrid o por Nicolás López Calera en Granada. Otro elemento que a mí personalmente me parece auspicioso es la, en algunos casos, estrecha vinculación intelectual entre iusfilósofos y filósofos de la moral; nombres como los de Javier Muguerza, Victoria Camps, Adela Cortina y Esperanza Guisán pueden ilustrar esta afirmación. Y creo que también es importante el hecho de que en los últimos años se haya ido imponiendo una forma de discutir los problemas que me recuerda el estilo de diálogo polémico que viví en Buenos Aires en la década del 60 y al que me he referido más arriba. Esta afirmación no responde a una arrogancia nacionalista sino a mi convicción de que sin una crítica despiadadamente racional no es posible el progreso científico.

En el caso argentino, SADAF permitió mantener la coherencia del grupo de orientación analítica. Recuperada la democracia, las universidades nacionales comienzan a reconquistar el prestigio perdido durante la dictadura militar. Esto, desde luego, en un marco de penuria financiera, que también afecta a la investigación en ciencias económicamente «poco exigentes» como suelen ser las filosóficas. En un reciente viaje a la Argentina, Robert Alexy me comentaba, con no poca admiración, la fuerza de voluntad y capacidad de sacrificio que significa para el universitario argentino dedicarse exclusivamente a la cátedra con sueldos que no 
guardan ninguna relación con el trabajo invertido. Si se piensa en la excelente dotación de medios materiales con que cuenta la universidad alemana, no es difícil comprender el comentario de Alexy.

Los problemas ético-políticos que plantea el paso de la dictadura a la democracia son objeto de discusión por parte de los filósofos del derecho, al igual que los temas de la reforma constitucional (Carlos S. Nino y Martín D. Farrell son buenos ejemplos al respecto). Esto me parece saludable pues invita a la coherencia y a la revisión de las relaciones entre ética y política. Como los políticos suelen tener la tendencia a plantear toda decisión éticamente significativa como una «elección trágica», pienso que no está de más mantenerse alerta a fin de evitar que extiendan demasiado el campo de estas últimas y tengamos que conformarnos con hacer las cosas a medias cuando pueden hacerse por entero, como solía decir Larra. Un exponente claro de un filósofo analítico en actitud de control y rechazo del imperio de argumentos exclusivamente prudenciales en la política es Jorge Bacqué, juez de la Corte Suprema de Justicia; su voto en disidencia con respecto a la constitucionalidad de la llamada «ley de la obediencia debida» es una pieza ejemplar de honestidad intelectual y ética.

Los tres países: Alemania, Argentina y España han sufrido dictaduras prolongadas y cruentas. Los tres padecen no sólo los daños emergentes de las mismas sino también el lucro cesante (para emplear términos jurídicos). Si los primeros pueden ser evaluados con relativa facilidad, los últimos sólo pueden apreciarse contrafácticamente. Por ello es difícil saber cuál hubiera sido la historia de la filosofía del derecho alemana sin el advenimiento del nacionalsocialismo o de la española sin la guerra civil o de la argentina sin Videla y sus cómplices. Lo que sí es claro es que en los tres casos se produjo la interrupción de una tradición intelectual, al menos a nivel institucional, y que estas interrupciones no se recuperan de la noche a la mañana. Tal vez no sea aventurado pensar que el «éxito» de la investigación ético-filosófica en el mundo anglosajón se deba en no poca medida a la continuidad de la tradición democrático-liberal y al aporte intelectual de quienes fueron expulsados por las dictaduras de la Europa continental.

6. -¿Cuál te parece que es la situación actual de la filosofía moral? ¿Cómo caracterizarías la teoría ética de los años 80? ¿Dónde te situarías tú en el panorama actual de la ética?

Quizás una buena vía para comprender el cambio de actitud por parte de los filósofos con respecto a la reflexión moral experimentado en las últimas décadas sea comparar los escritos que sobre estos temas se escribían todavía en la década de los cincuenta con algunos textos actuales; en 1958, por ejemplo, A. J. Ayer decía: «... las sentencias que simplemente expresan juicios morales no dicen nada» (en la pág. 133 de la edición castellana de Lenguaje, verdad y lógica, Buenos Aires, 1965). 
En 1984, David Gauthier sostenía que «elegir racionalmente es elegir moralmente» (Morals by Agreement, Oxford, pág. 4). Creo que ahora sería difícil sostener posiciones tan extremas como las de Ayer, sin que ello signifique que haya que caer en la equiparación de lo racional con lo moral. El movimiento que en Alemania se ha llamado «rehabilitación de la razón práctica» y al que están vinculadas diversas corrientes tales como las representadas por $\mathrm{J}$. Habermas, K. O. Apel o G. Patzig, y en el mundo anglosajón el «reconstructivismo moral» de un J. Rawls, procura ofrecer un intento de fundamentación racional de la ética que entronca con enfoques de tipo kantiano. También en las ciencias económicas es claramente perceptible un vuelco hacia los problemas éticos del mercado. El ejemplo más claro en este sentido es la obra de James Buchanan: basta comparar sus libros The limits of Liberty (1975) y Liberty, Market and State (1986) para comprobar un desarrollo que avanza desde una posición claramente no cognoscitivista hasta una línea que se asemeja a la mantenida por los neocontractualistas de origen kantiano. Esta preocupación por ofrecer fundamentos racionales de las normas éticas es sin duda la nota distintiva de la filosofía moral en la actualidad. En lengua castellana el representante más significativo de esta corriente, en la que también me incluyo, es Carlos S. Nino.

7. -En tu obra escrita hay un desplazamiento temático importante. En general, tus primeros trabajos abordaban problemas de teoría del Derecho, mientras que los de tu última fase versan principalmente sobre cuestiones de ética normativa. El desplazamiento, además, no se ha limitado a lo meramente temático. Aun a riesgo de simplificar, parece que puede decirse que mientras el background filosófico-moral de tus primeros trabajos era claramente no cognoscitivista (pensamos concretamente en tus críticas a las teorías basadas en la «naturaleza de las cosas»), en la actualidad sostienes posiciones en materia de ética (o de metaética) que tú mismo calificas de absolutistas. ¿Podrías explicar el proceso que te llevó a este cambio? ¿Hasta qué punto y en qué sentido te consideras en la actualidad un cognoscitivista en materia de ética? ¿Cómo te parece que se puede salvar el reproche usual que se suele dirigir al absolutismo ético, en el sentido de que va ligado a la defensa de concepciones políticas antiliberales?

Cuando comparo lo escrito en Derecho y «naturaleza de las cosas» con trabajos más recientes, llego a la conclusión de que en verdad no se trata tanto de un cambio de posición cuanto de temas. En aquel libro intentaba una crítica de posiciones que me parecían (y me siguen pareciendo) insostenibles por la simple razón de que violaban reglas lógicas elementales como es la que prohíbe inferir el deber ser desde el ser o se basaban en supuestos teológicos que difícilmente podía aceptar. Pero también ya en un trabajo remoto («Die Beziehungen zwischen Sein und Sollen», 1965), señalaba la importancia de los límites negativos que la realidad 
impone al legislador. La aceptación de la regla humeana no requiere ignorar el principio kantiano según el cual el deber ser presupone el poder ser o hacer. Esto significa que también en un intento de fundamentación racional de las normas éticas hay que tener en cuenta características antropológicas elementales como puede ser la autonomía individual de la persona. Los últimos trabajos que he publicado continúan esta línea de pensamiento.

Es verdad que la elección de los temas puede obedecer a motivaciones personales. El exilio, la ocupación profesional con temas de América Latina y la sensación de que el mundo en general parece acercarse cada vez más a situaciones éticamente insoportables ya que ponen en peligro la supervivencia del género humano, son sin duda factores que deben haber influido en la preocupación por ciertos problemas.

Si por cognoscitivistas se entiende la aceptación de criterios racionales que permiten designar a un comportamiento como éticamente correcto o no, me declaro cognoscitivista. Pienso que esto no es contradictorio con mi posición democrática-liberal. Por el contrario, una mala defensa de la democracia es sostener que ella presupone el relativismo ético. La tolerancia, por ejemplo, no puede ser la condescendencia boba que permite al nazi o al partidario del apartheid llevar a cabo sus propósitos o la indiferencia cínica que nos lleva a abstenernos de todo juicio de ética normativa con respecto a las costumbres morales de otros pueblos o épocas aduciendo que cada pueblo tiene su propia moral positiva y que ella debe ser éticamente aceptada. Es verdad que el principio de no dictadura, tal como fuera formulado, por ejemplo, por Arrow, es un elemento de la vida política democrática; pero este principio vale para el campo de lo negociable y no para lo que en algún trabajo he llamado el «coto vedado» de los derechos fundamentales. La defensa de ese «coto vedado», de lo no negociable, requiere éticamente la intolerancia o si se quiere la «dictadura» contra quienes pretendan invadirlo. Si no aceptamos este «coto vedado», no entiendo cómo puede asegurarse la vigencia de principios presupuestos por la democracia liberal como son los de la autonomía y la igualdad de coparticipación en la formación de la voluntad política. Si esto significa «absolutismo ético», no tengo nada que objetar en su contra. Pero esto en realidad no es nada nuevo ni patrimonio exclusivo de los llamados «cognoscitivistas»: basta leer el conocido escrito de Kelsen Vom Wesen und Wert der Demokratie (1929) para encontrar allí argumentos similares a los aquí expuestos. Juan Ruiz Manero, que edita actualmente en castellano los escritos políticos de Kelsen, podrá quizás querer matizar mis afirmaciones pero pienso que coincidirá conmigo en que no es casual que Kelsen inicie su estudio haciendo referencia a postulados de la razón práctica y que explique el funcionamiento del principio de la mayoría parlamentaria recurriendo a la protección de la minoría como «función esencial de los llamados derechos básicos y de libertad o derechos humanos y civiles, contenidos en todas las constituciones modernas de las democracias parlamentarias...» (pág. 53). La única fundamentación racional y la única defensa efectiva de la democracia representativa ha de partir pues de la aceptación de valores 
«absolutos» cuya protección requiere justamente el rechazo de un relativismo que sólo tiene cabida cuando se trata de la negociación parlamentaria de los deseos secundarios de la gente y no de aquellos bienes primarios, en el sentido de que son necesarios para la realización de todo «plan de vida» como diría J. Rawls o de toda «estrategia de felicidad personal», para usar una fórmula de $\mathrm{O}$. Höffe.

Si se quiere buscar otro principio «absoluto» de la democracia, puede pensarse en el valor de la publicidad de los actos de gobierno sostenida por Kant y que recientemente ha expuesto con gran claridad Javier de Lucas.

8. -Durante estos últimos años has ido publicando trabajos que abordaban problemas centrales de la ética contemporánea, como el tema de la desobediencia civil, de las relaciones entre Derecho y moral, de los deberes positivos y del paternalismo. Por otro lado, tu formación en el campo del Derecho y de la teoría política te sitúa en una condición "privilegiada» para abordar un tipo de trabajo de carácter más «sintético»y "generalista». ¿Está entre tus proyectos elaborar una teoría ética que integre todos esos problemas (que pudiéramos considerar de la «parte especial») y perspectivas? ¿Consideras que ha llegado el momento en tu obra de dar el paso de la "parte especial» a la «parte general»? ¿Sobre qué bases tendría que descansar, en tu opinión, un proyecto semejante?

Lo dicho precedentemente pienso que indica cuál es el enfoque que juzgo adecuado para el tratamiento de los problemas de ética normativa, que posiblemente me seguirán preocupando en los próximos 60 años (que no dudo viviré, justamente por fumar -violando las prohibiciones de Manolo Atienza- y no hacer demasiada gimnasia -desoyendo los consejos de los fanáticos del deporte, como Harmut Kliemt-). Es algo difícil de predecir si los trabajos puntuales pueden desembocar alguna vez en una «teoría general». Como creo en la labor eficiente de la hormiga y acepto el continuum de los granos y el montón, tal vez la coherencia que procuro mantener me permita formular consideraciones de tipo «general». Dentro del contexto de una realidad éticamente tan deficitaria como es la de los pueblos hispánicos, considero, por otra parte, que es conveniente analizar problemas concretos y tratar de proponer soluciones a los mismos. Esta pienso que ha sido la actitud asumida en otras latitudes por quienes realmente se han ocupado de cuestiones de ética normativa, tanto en el campo de la política como del Derecho. 